\title{
Learning Achievement Based on Electronic Learning among Freshmen Nursing Students
}

\author{
Napadon Leaudnakrob, Pisit Phuangnak, Kornwika Phromjuang, and Pisit Poltana
}

\begin{abstract}
The study was to develop, explore on effectiveness of an electronic learning (e-learning) on Anatomy and Physiology I on a "Muscular system", and investigate in learners' satisfaction related to the e-learning. Subjects were freshmen nursing students at Boromarajonani College of Nursing Uttaradit in Fall $2012(n=98)$. Questionnaires were the e-learning on Anatomy and Physiology $I$ on the "Muscular system", pre-test, practiced exercise, post-test, and learners' satisfaction. Statistical analyses were utilized on frequency, percentage, mean, and paired- $t$ test $(p<.05)$. Findings revealed that mean of ratio of score from pre-test before learning with the e-learning and post-test after utilizing on the e-learning with full score equaled 0.825 and 0.897 , respectively. The percentage of effectiveness of e-learning on Anatomy and Physiology I on the "Muscular system" was 86.50 in a good level. Overall mean of learners' satisfaction $(X=4.02)$ on the e-learning and each component on utilization $(X=4.12)$, presentation $(X=4.05)$, content $(X=3.92)$, and learning evaluation $(X=3.81)$ placed on the very good level, respectively. After nursing students participated in utilizing the e-learning, learning achievement was statistically significant higher than before studying on the e-learning $(p<.05)$.
\end{abstract}

Index Terms-Electronic learning, muscular system, and anatomy and physiology.

\section{INTRODUCTION}

Advanced Information Technology (IT) was increasing that affected on educational institutes. They had have to utilize on the IT to support and enhance successfulness of learners such as content preparation that has to be able to easily access via internet with maintaining on automatically feedback system to learners in order to improving effectiveness of learning activities [1]. Learning and teaching management with electronic learning (e-learning) considered that it can be utilized instead of traditional instruction with effectiveness and having high learning achievement [2], [3]. Because learning and teaching management on the e-learning emphasized on learners and activities of learning and teaching, learners can control learning process by themselves

Manuscript received February 10, 2013; revised June 12, 2013.

N. Leaudnakrob, P. Phuangnak, K. Phromjuang, and P. Poltana are with the Center of Excellent for Innovative Teaching and Learning Praboromarajchanok Institute for Health Workforce Development (PIHWD), Ministry of Public Health, Thailand (e-mail: 1_napadon@ hotmail.com, pisit_p2503@yahoo.com,kxp52@yahoo.com,ppoltana@hotmail.com).

N. Leaudnakrob and P. Phuangnak are with Boromarajonani College of Nursing, Uttaradit (UNC) under PIHWD, Ministry of Public Health, Amper Muang, Uttaradit Province, 53000 Thailand.

K. Phromjuang is with Boromarajonani College of Nursing, Buddhachinaraj (BNC) under PIHWD, Ministry of Public Health, Amper Muang, Pitsanulok Province, 65000 Thailand.

P. Poltana is with Boromarajonani College of Nursing Changwat Nonthaburi (BCNNON) under PIHWD, Ministry of Public Health, Amper Muang, Nonthaburi Province, 65000 Thailand. via internet networks from wherever and anytime [4] that create learning and teaching management on the e-learning, and it would be able on usefulness.

From teaching problems on Anatomy and Physiology I, a teacher-student ratio was unsuitable that affected on a lower score failed in a mild level; it should be improved levels. Moreover, it was wasted time, money, and opportunity on studying. From observations, learners were lacking of motivation on participation on activities, being deficient in co-learning, creating poor of team working, and having short of communication channel between learners and teachers. Thus, a learning plan has to be improved to enhance the learning achieved level. Researchers generated learning lessons on Anatomy and Physiology I with the e-learning on the "Muscular system". Content consisted of 1) muscular types, 2) structure, components, general characteristics, and 3) contraction mechanism such as striated muscle, smooth muscle, and cardiac muscle. The study was to develop, explore on effectiveness of the e-learning on Anatomy and Physiology I on the "Muscular system", and investigate in learners' satisfaction on the e-learning. Research utilization was applied to develop content and e-learning lessons, including increasing skills of utilization of Information and Communication Technology (ICT) for learning, improving on enthusiasm, and raising learners' interesting. It would be useful for teaching and learning systematic development.

Research objectives were 1) to compare learning achievement before and after utilizing on the e-learning on Anatomy and Physiology I on the "Muscular system", 2) to explore effectiveness of the e-learning on Anatomy and Physiology I on the "Muscular system", and 3) to investigate on learners' satisfaction among freshmen nursing students on the e-learning on Anatomy and Physiology I on the "Muscular system".

\section{LITERATURE REVIEW}

The e-learning was utilizing as instrument for improving opportunity on education, creating of models, motivating learning and teaching emphasized on thinking process, selling idea, and participating on learning process between learners and teachers. In the 19th century, the concept was conducted in colleges that were taught by applying on video tape, distributing of pictures and sound via satellite, and sending signal via cable wires. Currently, learning and teaching models were succinctly developed [5]. Learning and teaching via the e-learning still exist with problems in an educational system. First, learners from civilized countries have higher skills and ability on utilizing on operating system, including on applying of a word processing program, searching on internet, and using on electronic post office than 
learners who live in poor countries. Second, subjects on the IT era are always core subjects for freshmen students that would create having various learners and having different methods of teaching. Third, instrument and computer programs often outdated after students graduated about 3 years [6]. Thereby, researchers noticed opportunity to bring learning and teaching management via the e-learning that accomplished in developing countries in applying suitably learners, environment, and situation in Thailand.

Learning Management System (LMS) is software that handles with learning and teaching management via website, including facilitating instrument such as teachers, learners, and admin who takes care of a computer system. The LMS consists of 5 components such as 1) curriculum management system, 2) creating lesson system, 3) testing and evaluating system, 4) promoting learning system, and 5) data management system [7]. Program that creates the LMS compounds of 2 types such as opened source LMS with privilege on a GPL Modular Object-Oriented Dynamic Learning Environment (Moodle), and commercial LMS that was developed by private agency for selling by Al-Ajlan and Zedan [1]. Comparing the Moodle program with other programs in the same group showed that the suitable Moodle program was chose to apply with many subjects. The authors concluded of advantages of the Moodle program such as 1) providing free for utilization based on privilege of GNU, 2) managing content on each subject, preparing on content, learning evaluated document, exchanging opinion, and participating on blackboard between learners, 3) establishing on software machine that mostly uses Apache Web Server utilized MySQL as database and a supporting program, 4) reserving educational design based on well educational theory, 5) setting up and applying without modifying or fixing system with research as above. Thus, this research utilized the Moodle program on this study.

\section{MATHODOLOGY}

The descriptive research was to explore learning achievement on Anatomy and Physiology I on the "Muscular system" and to investigate on learners' satisfaction among freshmen nursing students on the e-learning on Anatomy and Physiology I on the "Muscular system" at Boromarajonani College of Nursing Uttaradit in Fall 2012 ( $n=98)$. Questionnaires were 1) the e-learning on Anatomy and Physiology I on the "Muscular system", 2) pre-test and post-test before learning with the e-learning (30 items), 3) learners' satisfaction on the e-learning on the "Muscular system" (33 items) with 5 rating scales such as strongly agree (5), somewhat agree (4), moderated agree (3), somewhat disagree (2), and strongly disagree (1). Cronbach's alpha coefficient was analyzed on reliability $(\alpha=0.87)$. Learners' satisfied levels scored to 5 levels such as strongly agree (4.21-5.00), somewhat agree (3.41-4.20), moderated agree (2.61-3.40), somewhat disagree (1.81-2.60), and strongly disagree (1.00-1.80), respectively.

Collective data were done. Researchers provided pre-test before utilizing on the e-learning about 30 items. Learners had to study by using the e-learning on website http://ceiltaplms.pi.ac.th on the "Muscular system" after that post-test (30 items) was operated after utilizing on the e-learning. Learners' satisfaction on the e-learning was analyzed by utilizing on frequency, percentage, mean, and Standard Deviation (S.D.). The effectiveness of utilizing on e-learning was analyzed by employing on a mean ratio before learning on pre-test, full score $\left(E_{a}\right)$, the mean ratio after learning on post-test, and full score $\left(E_{b}\right)$. Comparing mean on before and after utilizing on the e-learning was done by analyzing on paired- $t$ test $(p<.05)$.

\section{RESUlts}

From the e-learning development on Anatomy and Physiology I on the "Muscular system", findings revealed as follow.

- The effectiveness of the e-learning on Anatomy and Physiology I on the "Muscular system" after modifying and developing on the e-learning was done. Researchers applied the e-learning for investigating on the effectiveness that discussed below.

1) Pre-test before studying with the e-learning was analyzed $(12$ score from $30=61.2 \%$, mean $=8.1$, S.D. $1.02, n=60)$. Mean ratio on the pre-test and full score $\left(E_{a}\right)$ equaled 0.825 .

2) Post-test after studying with the e-learning (25 score from $30=66.32 \%$, mean $=22.3$, S.D. $=1.42$. Mean ratio on post-test and full score $\left(E_{b}\right)$ equaled 0.897 .

3) The effectiveness of the e-learning on Anatomy and Physiology I on the "Muscular system" was about $86.05 \%$ compared with standard of e-CAL that discovered in the good level.

4) Learning achievement of the e-learning after studying with the e-learning on Anatomy and Physiology I on the "Muscular system" was higher than before studying with the e-learning $(p<.05)$.

- Regarding to learners' satisfaction among freshmen nursing students on the e-learning on Anatomy and Physiology on the "Muscular system", overall placed on the great level $(X=4.02$, S.D. $=.71)$. On each aspect, mean placed on the great level ranged from 3.50 to 4.50 such as utilization $(X=4.12, S . D .=.82)$, presentation $(X$ $=4.05$, S.D. $=.82)$, content $(X=3.92$, S.D. $=1.01)$, and learning evaluation $(X=3.81, S . D .=1.12)$, respectively.

\section{DisCUSSION AND CONCLUSION}

The study was to develop and explore the effectiveness of utilizing on the e-learning on Anatomy and Physiology I on the "Muscular System" that built up the usefulness on the great level $(86.05 \%)$. It stated that this e-learning constructed actual learners on learning. The learners were higher learning achievement that post-test score was higher than pre-test score, and the mean after studying with the e-learning was higher before studying with the e-learning. According with Pachsaichon (2006) [8], the study on developing on lessons of the Computer Assisted Instruction (CAI) on Biomechanics of muscle testing and measuring on movement duration in sophomore Physical Therapy students $(n=30)$ explored that 1$)$ the CAI was higher effectiveness than normal standard at $85.33 / 87.67,2$ ) learning achievement by utilizing on the CAI 
was statistically significant higher than learning documentation $(p<.05)$. From the study, it would cause from learning with the e-learning with participating online network. Learners could be able to study on content lessons and inquired on each aspect of problems with teachers in wherever, whenever, and that would make learners be trained with other friends. Learners could generate knowledge from data and information because learners have to search of knowledge and construct comprehension by themselves. They could be capable on utilizing on the IT and communication on studying data and information from world knowledge assets that publish throughout the world. Thus, students would increase learning achievement for themselves.

The presentation of lessons with processing models on developing the e-learning lessons was in attendance content on orderly first heading and last heading. Learners can read content and watch pictures on each topic that fits for presentation or accepted-teaching on basic information. It easily rememorizes and be suitable for teaching on many students to enhance effectiveness on constant content for large groups of learners [4]. Thereby, it does not fit for presenting on difficult content and most abstract. Lessons should be presented on content related to teaching strategies that learners could picture or intangibly conceptualize based on creating simulation. The application on slide multilearning and mobile pictures with sound should be utilized [9]. For learning effectively with the Moodle, learners have to self responsibility on a virtual classroom for studying content and practicing the tests by themselves. The LMS with the Moodle will record profile and track learners by recording learners' activities, including verifying pre-test score, collecting score during learning, and accumulating post-test score on database of the Moodle system [10]. The learners can be promptly able to know their progressing learning when accessing on the system. Therefore, learning and teaching in the e-learning environment with developing lessons would make learners enthusiastic on learning and increase on interesting content. All reasons illustrated why learning achievement after participating on the e-learning had have higher score than before studying with the e-learning that learners did not have content knowledge on the lessons.

Findings on developing of the e-learning on Anatomy and Physiology I on the "Muscular System" confirmed that teaching with the e-learning will enhance effectiveness on education both of teachers and learners because it was learning on managing learning experience to learners. It also catalyzed learning activities in different forms, including improving document, textbook, and books [11]. In fact, all textbooks have only words or immobile pictures. However, the e-learning composites on animation pictures and different sounds that would be beneficial for teachers and convenient teaching and saving time. Moreover, learners will have higher learning achieved score.

\section{REFERENCES}

[1] A. A. Ajlan and H. Zedan, "Why Moodle," $12^{\text {th }}$ IEEE International Workshop on Future Trends of Distributed Computing Systems, pp. $58-64,2008$
[2] T. Adseenak, "Comparing on learning achievement with Computer Assisted Instruction on e-learning with normal teaching on Technology for learning (Rajchapat curriculum, 1999)," Master thesis on Faculty of Industrial Education. Faculty of Industrial Education of King Mongkut's University of Technology North Bangkok or Technology Pranakorn Nuah, 2005.

[3] S. Tipsugnern, "Construction and exploration on the effectiveness of e-Learning: Basic knowledge on computer and internet for high school students, Department of General Education." Master thesis on Faculty of Industrial Education. Faculty of Industrial Education of King Mongkut's University of Technology North Bangkok or Technology Pranakorn Nuah, 2004

[4] T. Lougjaratsang. (2009). Meaning of Electronic learning (E-learning). [Online] Available: http://www.kroobannok.com/view.php.article id-1586.

[5] L. A. Halawi, R. V. McCarthy, and S. Pires, "An Evaluation of E-Learning on the Basis of Bloom's Taxonomy: An Exploratory Study," Journal of Education for Business, vol. 84, pp.374-380, 2009.

[6] D. Sudpakdee, "Information and communication technologies with lifelong learning," Learning and Teaching Innovation, vol. 4, no. 2, pp. 9-11, May-August, 2008.

[7] Moodle.org. (2010). The Moodle LMS. [Online]. Available: http://moodle.org/.

[8] A. Paksaichon, "Lesson development on Computer Assissted Instruction (CAI) on Biomechanics entitled "Muscle testing and mobility duration' from freshmen Physical Therapy students," Developing Learning and Teaching of Rungsit University. vol. 1, no. 2, pp. 24-35, 2007.

[9] R. C. Clank and R. E. Mayer, E-Learning and the science of instruction, New York: John Wiley \& Sons, Inc, 2003.

[10] Moodle.org. (2008). Welcome to Moodle. [Online]. Available: http://www.moodle.org.

[11] G. W. Juette and L. E. Zeffanella, "Radio noise currents n short sections on bundle conductors," presented at the IEEE Summer Power Meeting, Dallas, TX, June 22-27, 1990.

[12] J. Williams. Narrow-band analyzer. Ph.D. dissertation, Dept. Elect. Eng., Harvard Univ., Cambridge, MA, 1993. Aroonpiboon, B. 2007. Moodle e-Learning. Developing content of digital electronic at techonology learning center and national computer. [Online]. Available: http://www.learnsquare.com/index.php?mod=Courses\&op=lesson_sh ow $\&$ cid $=131 \&$ sid $=\& l i d=1538$.

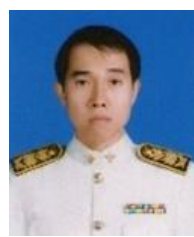

Napadon Leaudnakrob was born at Prae Province, Thailand in 1972. He got a diploma on nursing science equivalent to Bachelor of Science in Nursing in 1993 from Boromarajonani College of Nursing, Sawanpracharak, Praboromarajchanok Institute for Health Workforce Development (PHWD), Ministry of Public Health, Thailand. He also graduated in a master's degree of Medical Science (M.S.) in Medical Physiology from Khon Kaen University in 1999. He is currently a lecturer at the Boromrajonani College of Nursing Uttaradit (UNC). His research focuses on e-learning, measurement and evaluation, and Internet Computer Technology (ICT)

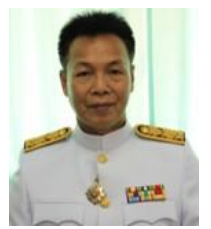

Pisit Phuangnak was born at Nakornsawan Province, Thailand in 1960. He graduated from Sirindhorn College of Public Health, Pitsanulok on an associated degree in 1983. He also got a bachelor degree in Public Health from Mahidol University in 1991. He is currently a full-time lecturer at the General of Education department at Boromarajonani College of Nursing Uttaradit (UNC). His research focuses on statistics and research related on public health.

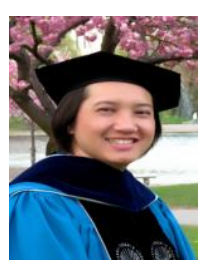

Kornwika Phromjuang was born at Uttaradit Province, Thailand on October 25, 1973. She got a diploma on nursing science equivalent to Bachelor of Science in Nursing on March 15, 1995 from Boromarajonani College of Nursing, Uttaradit (UNC), Praboromarajchanok Institute for Health Workforce Development (PIHWD), Ministry of Public Health, Thailand. She graduated in Nursing Administration on her $1^{\text {st }}$ Master in the Nursing Science (M.N.S) degree on June 4, 1999 from Faculty of nursing, Chulalongkorn University, Bangkok, Thailand. On April 15, 01, she got the Royal Thai Government Scholarship for furthering study in Master and $\mathrm{PhD}$ programs focusing on Gerontological nursing in the U.S.A. from the PIHWD, Ministry of Public Health, 
Thailand on July 29, 2002 for studying on MSN and $\mathrm{PhD}$ at U.S.A. She was graduated in the $2^{\text {nd }}$ Master Science in Nursing (M.S.N) on January 14, 2005 on Clinical Nurse Specialist (CNS) focusing on acute care on medical-surgical nursing from France Payne Bolton School of Nursing (FPB) Case Western Reserve University (CWRU), Cleveland, OH, U.S.A. She was also graduated on her $\mathrm{PhD}$ (gerontological nursing) on May 18 , 2008 from the FPB, CWRU, Cleveland, OH, U.S.A. as well.

Dr. Phromjuang was working as a nursing instructor from 1995 to 2002 at the UNC before going to study on the master and $\mathrm{PhD}$ at the U.S.A. After she graduated on her $\mathrm{PhD}$ in 2008, she was working at Boromarajonani College of Nursing, Lampang under the PIHWD as a professional level from 2008-2010. She has been working as the nursing instructor on a senior professional level at Boromarajonani College of Nursing, Buddhachinaraj (BNC) at Pitsanulok Province under the PIHWD since June, 2010. Her research interests focus on health promotion behavior among diabetic elderly, wound care nursing, pain management, emergency nursing, and clinical nursing related to elderly patients on acute care.

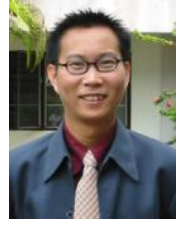

Pisit Poltana was born at Nan Province, Thailand in 1971. He got a diploma on nursing science equivalent to Bachelor of Science in Nursing in 1993 from Boromarajonani College of Nursing, Sawanpracharak, Praboromarajchanok Institute for Health Workforce Development (PIHWD), Ministry of Public Health, Thailand. He graduated in a master's degree of Master of Science at Mahidol University in 1997. He also graduated in Doctor of Philosophy in Anatomy, Faculty of Graduate Studies, Mahidol University, Thailand in 2005.

Dr. Pisit Poltana works as the Deputy Director of Supporting Academic Department, Boromrajonani College of Nursing, Changwat Nonthaburi, Thailand. He also holds on the Director of Center of Excellence for Innovative Learning and Teaching in Anatomy and Physiology, Praboromarajchanok Institute (CEILTAP) for Health Workforce Development (PIHWD), Ministry of Public Health, Thailand. His research interests focus on Anatomy, Physiology, e-learning, Polychaete, and aquaculture. 